\title{
LITERATURA INFANTIL E ANCESTRALIDADE AFRICANA: o que nos contam as crianças? ${ }^{1}$
}

\author{
Débora Oyayomi Araujo ${ }^{2}$
}

Resumo: Imiscuída nas tendências da literatura infantil de temática da cultura africana e afro-brasileira está a ligação entre as crianças e a ancestralidade, talvez porque a criança seja diretamente afetada pelo encantamento do mundo a sua volta. É seguindo essa pista que este texto analisa como personagens negras da literatura infantil brasileira e africana lidam com os seres viventes e não viventes e como aprendem e apreendem o mundo a partir do contato com o sagrado. Nessa busca, dois elementos se destacam: a comunidade e o espírito ancestral. São eles que evidenciam o quanto a criança é protagonista do vínculo que mantemos com nossas origens e forças espirituais.

Palavras-chave: Criança; Espírito ancestral; Literatura infantil.

\section{CHILDREN'S LITERATURE AND ANCESTRY AFRICAN: what children tell us?}

\begin{abstract}
Within the tendencies of children's literature with themes related to African and Afro-Brazilian culture is the connection between children and ancestry, perhaps because the child is directly affected by the enchantment of the world around them. It is following this clue that the present article explores how black characters of Brazilian and African children's literature deal with living and non-living beings and how they learn and apprehend the world from contact with the sacred. In this search, two elements stand out: the community and the ancestral spirit. It is they that show how much the child is protagonist of the bond that we maintain with our origins and spiritual forces.
\end{abstract}

Keywords: Child; Ancestral spirit; Children's literature.

\section{Pra começo de conversa}

Muriquinho piquinino, muriquinho piquinino, Parente de quiçamba na cacunda. Purugunta aonde vai, purugunta aonde vai, Ô parente, pro quilombo do dumbá. $\hat{\mathrm{E}}$, chora, chora gongo, ê devera, chora gongo chora, $\hat{\mathrm{E}}$, chora, chora gongo, ê cambada, chora gongo chora.

Clementina de Jesus ${ }^{3}$

As cantigas, as histórias de outras terras e, sobretudo, a corporeidade marcada das avós e dos avôs foram e ainda são, para a população negra no Brasil, grandes patrimônios histórico-culturais. A musicalidade não se expressa somente no canto, como este interpretado por Clementina de Jesus, mas também nos sotaques, no idioma que aciona memórias afetivas e nos traços ancestrais ditos em palavras tão intrigantes a

\footnotetext{
${ }^{1}$ Dedico este artigo aos membros do LitERÊtura - Grupo de estudos e pesquisas em diversidade étnico-racial, literatura infantil e demais produtos culturais para a infância, grupo responsável por me estimular a seguir uma vida acadêmica não adoecedora, mais alegre e mais crianceira. Agradeço especialmente à Sarita Faustino, Mariana Souza, Helom Oliveira, Victor de Jesus e Luís Thiago Freire Dantas pela leitura atenta e contribuições feitas para o aprimoramento do texto.

2 Iyawo de Oyá, no Ile Așè Ojugbo Ògún. Doutora e mestra em Educação pela UFPR, licenciada em Letras - Português/Inglês (Unespar). Professora do Centro de Educação da Universidade Federal do Espírito Santo, no Departamento de Teorias do Ensino e Práticas Educacionais, atuando na disciplina de Educação das Relações Étnico-Raciais, e do Programa de PósGraduação de Mestrado Profissional em Educação (PPGMPE/Ufes).

${ }^{3}$ Intérprete: Clementina de Jesus. Recolhido por Aires da Mata Machado Filho, na região de São João da Chapada, município de Diamantina - Minas Gerais.
} 
nós, no ocidente. O que significa "dumbá”? E “cambada", terá o mesmo significado na origem do que tem para nós? Tais pistas, deixadas numa espécie de traço diaspórico de antepassados africanos que para cá vieram na condição de sequestrados, estimulam o desejo de refazer o caminho para reconhecer sua história, ainda que sabendo que um caminho nunca é igual ao outro.

A música cantada por Clementina me faz lembrar de kokota, um termo usado por meu avô Eurico Anacleto de Araújo, mineiro da região do Cerro, quando queria fazer um carinho nos netos e netas. Dizia ele: "Vem aqui mô fio, pô vô dá uma kokota". "Mô fio" era uma expressão destinada a meninos e meninas - assim como "fião", termo que meu pai utiliza até hoje para mim, como forma carinhosa de chamar sua primogênita. Mas kokota era, verdadeiramente, ou "em deveras", como dizia meu avô, muito engraçada, pois consistia na ação de ele tocar nossas bochechas simulando um beijo, mas escondendo os lábios entre os dentes e emitindo um som oco e estalado. Assim, ele parecia ser muito mais velho do que era e desdentado. Kokota. E agora, folheando os livros de literatura infantil, descubro, via Kalimba, obra da escritora angolana Maria Celestina Fernandes (2015), que kota significa "pessoa mais velha, idoso". Então, como uma dedução quase que infantil (e ser infantil neste texto não será um adjetivo pejorativo) e no intenso exercício de reconexão com minha ancestralidade, interpreto que kokota é um beijo de velho!

Assim tem sido o universo das crianças no Brasil, metaforicamente aqui entendidas como aquelas que descendem dos africanos: o de se reconectar, por meio de pistas, à sua história. Afinal, como nos ensinou Chico César (1996): "Filhinho tem que entender / Mama África vai e vem / Mas não se afasta de você”.

Esse desejo de reconexão está também bastante presente na literatura infantil. Tem aumentado o número de produções nacionais que exploram o que Eliane Debus (2017, p. 26) define como "temática da cultura e história africana e afro-brasileira": "uma literatura que traz como temática a cultura africana e afro-brasileira, sem focalizar aquele que escreve (a autoria), mas sim o que tematiza". Tal expressão e definição serão tomadas como referência neste texto.

Além do aumento, uma significativa ampliação das redes de tradução e importação de obras africanas tem possibilitado, no Brasil, o contato com textos em prosa e em verso de autoras e autores daquele continente. Esse movimento recente pode ser considerado uma tendência da produção literária infantil neste país, por evidenciar uma aproximação escrita antes pouco comum entre as culturas africanas e afro- 
brasileiras. Mas especialmente tal tendência tem como característica um "resgate da herança e da ancestralidade africana" (ARAUJO, 2017, p. 38). As obras dessa categoria:

[...] são fortemente carregadas de histórias míticas sobre a criação do mundo, sobre a resolução de conflitos e sobre a capacidade de resistência de povos africanos, seja em contextos locais ou na diáspora africana. Envolvem personagens com atributos sobre-humanos, dotados de poderes mágicos ou de uma sabedoria ancestral; são também deusas e deuses que auxiliam seus descendentes na resolução de conflitos; são, sobretudo, histórias de reencontros entre três experiências: a vivência com o racismo, que marca tão fortemente as trajetórias de negras e negros no Brasil; a resistência, característica central da população negra na diáspora; e seus mitos fundantes, que na origem africana auxiliavam mulheres, homens, crianças, velhas e velhos a lidarem com seus conflitos e a solucionarem problemas. São histórias de reconciliação e de fortalecimento da história africana (ARAUJO, 2017, p. 38).

É tomando essa tendência como pista que neste artigo serão explorados dois elementos concernentes às crianças negras, personagens da literatura infantil de temática da cultura africana e afro-brasileira: a comunidade e o espírito ancestral. Conforme será apresentado nas seções seguintes, tais elementos evidenciam a relevância da criança ${ }^{4}$ na organização do mundo. Sua ação será reflexo, neste texto, de um exercício, tal como propõe Jorge Larrosa (1998, p. 70), de "devolver à infância sua presença enigmática e de encontrar a medida de nossa responsabilidade na resposta diante da exigência que esse enigma traz consigo". Tal presença "enigmática" significa, para o ocidente, a compreensão da criança como outro, pois a infância "não é nunca o que sabemos [...]; não é nunca a presa de nosso poder (é o outro que não pode ser submetido), mas, ao mesmo tempo, requer nossa iniciativa; não está nunca no lugar que lhe damos [...], mas devemos abrir um lugar que a receba" (LARROSA, 1998, p. 70). Mas enigma não seria a palavra mais adequada para Sobonfu Somé (2007): nos contextos tradicionais africanos, ela considera que a criança é ritualística, devido à sua estreita ligação com os espíritos. Assim:

A presença das crianças gera os rituais mais simples e vibrantes. Quando estão presentes, o que quer que se faça de errado torna-se certo. Por alguma razão, elas são, por sua própria natureza, ritualísticas. Mesmo que você simplesmente as reúna, chame os espíritos, declare seu propósito e faça uma procissão liderada pelas crianças - só isso já estará bem. A quantidade de sinceridade e pureza que caminhará à sua frente curará todos os tipos de impurezas ou críticas e negatividade que

\footnotetext{
${ }^{4}$ A partir daqui demarcando-a em sua faixa etária convencional.
} 
você possa estar carregando. É assim, poderoso (SOMÉ, 2007, p. 61).

Contudo, a imagem, seja ela enigmática ou ritualística (ou ambas), não pode conferir nenhum caráter de exotização à criança, em qualquer sociedade que ela estiver. Para quem se propõe a pensar a criança e a infância em sua alteridade racial, não é possível categorizá-las no que venho chamando de "inho/a": ao ser questionada sobre minha área de pesquisa, por exemplo, e respondo que estudo literatura infantil de temática da cultura africana e afro-brasileira, logo recebo como réplica expressões como: “Ai que bonitinho!”. Criancinha, bonitinha, livrinho... Por extensão, não somente a criança mas tudo a ela relacionada - inclusive pesquisadoras e pesquisadores adultos - são associados à ideia de menoridade, no sentido pejorativo. É necessário, portanto, alguma ação e ela tem sido tomada à medida que venho avançando nos estudos sobre literatura infantil, crianças e infâncias: ressignificando o que é possível e refutando o que (ainda) não é possível modificar. É válido ressignificar, por exemplo, o que deriva de infância: ser infantil não é ser imaturo; é antes pensar o mundo a partir de perspectivas diversas ou, em outras palavras, de uma alteridade responsável por levar a nós, adultas e adultos, "a uma região na qual não regem as medidas de nosso saber e de nosso poder" (LARROSA, 1998, p. 70).

Tomo como exemplo a voz de uma criança chamada Maria, do livro Cadernos sem rimas da Maria, de Lázaro Ramos. Seu irmão, João, personagem do livro Cadernos de rima do João, do mesmo autor, "[e]screveu várias palavras e começou a missão de explicar sempre em rima o que lhe manda o coração" (RAMOS, 2016). Já ela, em resposta, assim disse:

\footnotetext{
RIMA é bom

ARTE nobre, coisa Fina.

Mas não gosto, é meu direito. E também sobe minha crina quando dizem: Não faça isso, não queira aquilo, não é coisa de menina! $\mathrm{O}$ caderno é legal e me ensina, mas minha história é de outro jeito, eu não sou dessa rotina. Se quiser, eu uso prosa, verso, conto: isso é o que me fascina. Joãozinho ri do meu jeito e me chama de 'atralhapalhante'.

Ele inventou uma palavra! Então daqui sigo adiante...

Este é meu caderno sem rimas e com palavras inventadas!

(RAMOS, 2018).
}

A partir de tal demonstração, demarco, neste texto, que as vozes das crianças, personagens das obras literárias escolhidas (e outras crianças narradas em experiências reais), serão acionadas como fontes argumentativas na mesma medida que as vozes 
adultas. Essa é uma das consequências da ressignificação do papel das crianças e das infâncias: suas vozes não são mais objeto de estudo, mas sim protagonistas das problemáticas científico-acadêmicas.

Já o que não tem sido possível ressignificar, como a ideia de menor ${ }^{5}$, por exemplo, vem sendo questionado e enfrentado a partir do que constou Fúlvia Rosemberg (2012, p. 12): “a fase da criança pequena [...] constitui um tempo social discriminado pela sociedade brasileira, nos campos acadêmicos e político, inclusive pelos chamados novos movimentos sociais". Ainda que a autora adote o enfoque de que "as relações de idade (e não a infância) constituem categoria analítica útil para se compreender a produção e sustentação de desigualdades [...]” Rosemberg (2012, p. 26), sua perspectiva é aqui tomada para acionar e denunciar o caráter adultocêntrico da produção acadêmica. Assim, "menor" é um termo ainda pejorativo por hierarquizar as etapas da vida. E tal hierarquização estende-se também para os gêneros, já que há uma "reconstrução da construção da identidade de gênero na infância à luz da bipolaridade masculino/feminino, conforme marca a etapa adulta" (ROSEMBERG, 2012, p. 29). Cabe o constante exercício da não conformação, portanto, do caráter de menoridade atribuído à criança.

Dessa maneira, a proposta aqui é de provocar as frentes convencionais de pensamento sobre as infâncias, mas a partir de uma perspectiva especial: as relações ancestrais presentes nas experiências das crianças na literatura infantil de temática da cultura africana e afro-brasileira. Como elas lidam com os seres viventes e não viventes? Como aprendem e apreendem o mundo a partir do contato com o sagrado? A busca por respostas a essas perguntas levam aos dois elementos antes anunciados: a comunidade e o espírito ancestral. Tais elementos tornam-se uma espécie de díade recorrente nas produções literárias africanas e uma marca diaspórica nas produções brasileiras, realçando o quanto a ideia de indivíduo só é possível pela existência de um conjunto de aspectos que envolvem o todo (os animais e os humanos - viventes e não

\footnotetext{
${ }^{5}$ Ainda que argumente nesse momento não ser possível pensar uma noção positiva de menor, ressalto que ela já foi explorada por outros autores em contextos próprios. Para Gilles Deleuze e Félix Guattari (1977, p. 25), por exemplo, a "literatura menor" é uma literatura relacionada à produção de um grupo em processo de desterritorialização: "uma literatura menor não é a de uma língua menor, mas antes a que uma minoria faz em uma língua maior". E a partir de tal definição, Sílvio Gallo (2002, p. 169) pensou a noção de menor em relação à educação: "Para aquém e para além de uma educação maior, aquela das políticas, dos ministérios e secretarias, dos gabinetes, há também uma educação menor, da sala de aula, do cotidiano de professores e alunos. É essa educação menor que nos permite sermos revolucionários, na medida em que alguma revolução ainda faz sentido na educação em nossos dias. A educação menor constitui-se, assim, num empreendimento de militância".
} 
viventes -; os objetos; e a natureza). Isso aciona outro intento deste artigo: ampliar os modos de ver o mundo e a vida a nossa volta, tendo a criança como motor organizador.

Assim, ainda que as personagens infantis que compõem este texto sejam, em sua grande maioria, fictícias, ouvi-las na literatura infantil é extremamente importante, sobretudo porque se a produção literária endereçada às crianças é pouco considerada, muito mais o é quando se trata de obras com temática da cultura africana e afrobrasileira. É por isso que a investigação sobre infâncias e literaturas que tematizam as crianças negras costuma ser um exercício de denúncia da desigualdade e da hierarquização em relação à representatividade. Mas não refutando a importância dessa perspectiva investigativa, neste texto em especial o foco será outro: identificar o que as vozes literárias das crianças negras informam sobre suas infâncias e trajetórias, tomando a experiência espiritual como princípio.

Nesse sentido, este texto inicialmente discutirá a força da comunidade para a criança, considerando também o caráter limitado que envolve a tentativa de educá-la de modo sozinho ou com duas pessoas (como ocidentalmente pensamos a organização e as responsabilidades familiares). Como seres humanos, somos limitados quanto ao que podemos fazer ou dar a ela. O famoso ditado atribuído às sociedades tradicionais africanas que diz que é preciso uma aldeia inteira para educar uma criança é, realmente, o fundamento dessa compreensão de comunidade.

Em seguida serão exploradas as maneiras como as vozes literárias infantis lidam com o espírito ancestral que circunda suas vidas, considerando que a relação da criança com a ancestralidade caracteriza-se, primordialmente, pela proximidade entre ambos, conforme exemplifica Somé (2007, p. 68): “o povo de nossa aldeia diz que as crianças não pertencem completamente aos pais que lhes dão a luz; diz que elas usaram o corpo de seus pais para chegar, mas pertencem à comunidade e ao espírito".

\section{A força da comunidade}

É na interação com o grupo que os laços afetivos, estéticos e culturais da criança são fortalecidos. Talvez por isso a ideia de comunidade seja um elemento realçado na produção literária de temática da cultura africana e afro-brasileira. É também na comunidade que a criança amplia seu repertório sociocultural. Na obra autobiográfica Amkoullel, o menino fula, o escritor Amadou Hampâté Bâ (2003) destaca, por exemplo, a importância da convivência em comunidade, em especial com os griots, para a 
aprendizagem das crianças:

Neste aparente caos aprendíamos e retínhamos muitas coisas, sem dificuldade e com grande prazer, porque tudo era muito vivo e divertido. 'Instruir brincando' sempre foi um grande princípio dos antigos mestres malineses. Mais do que tudo, o meio familiar era para uma grande escola permanente; a escola dos mestres da palavra (BÂ, 2003, p. 175).

Os "mestres da palavra" ou, nas palavras de Dalzira Maria Aparecida Iyagunã (2013), os "mais velhos" são aqueles responsáveis pela transmissão do conhecimento aos mais jovens: "quanto mais velho mais sábio. Tanto é que a criança e o jovem ouviam os velhos e lhes devotavam respeito" (IYAGUNÃ, 2013, p. 66). É o mesmo que nos conta Wangari Maathai (2007), em sua obra autobiográfica ${ }^{6}$, em que ressalta o papel da mulher como contadora de histórias. Nascida no Quênia, na etnia quicuia, ela e as demais crianças vivenciavam experiências ricas de aprendizado ligado às suas mães, tias e avós:

A arte de contar histórias ao redor da fogueira era uma dimensão essencial da vida rural. Muitas noites, no final de um dia de trabalho no campo, as crianças se reuniam para ouvir as histórias que suas mães contavam, enquanto esperavam o jantar cozinhar na fogueira ou num fogareiro de três pedras. [...] As histórias quicuias serviam para entreter, educar e estimular a criatividade das crianças. Era um sistema de educação informal bem eficaz.

[...]

Eu adorava aquele clima calmo e acolhedor: nós ali, sentados, ouvindo o que nos contavam as mulheres - mães, tias, avós. (Os homens não contavam histórias.) (MAATHAI, 2007, p. 72).

Grandes lições se aprendem em comunidade e a partir dela. Foi o que descobriu, por exemplo, a personagem Mama Panya, por meio de seu filho Adika. Ao chamar o menino para irem juntos ao mercado comprar ingredientes para o preparo de panquecas, sua preocupação foi aumentando à medida que seguiam pela estrada, pois Adika convidava cada pessoa que encontrava: convidou $\mathrm{Mzee}^{7}$ Odolo, o amigo mais velho da família, que estava pescando no rio; depois chamou Swandi e Naiman, duas amigas dele que estavam pastorando o gado às margens da estrada; em seguida, já no mercado, na banca das bananas, convidou Gamila, sua amiga de escola; também Bibi e Bwana Zamenna, vendedoras de farinha; além de Kaya, vendedora da banca de especiarias.

\footnotetext{
${ }^{6}$ Agradeço ao Íkaro Brumatti Alvarenga, por ter me presenteado com o livro de Wangari Maathai. Ele chegou às minhas mãos justamente no momento de escrita deste texto.

7 “Palavra kiswahili que significa 'homem mais velho respeitado"” (MAATHAI, 2007, p. 130).
} 
Preocupada, Mama Panya alertou o filho:

- Ai-yi-li! Você e eu temos sorte se conseguirmos dividir uma panqueca!

- Mas, Mama, nós teremos um pouco e um pouquinho mais.

[...]

No caminho de volta para casa, Mama perguntou:

- Quantas pessoas convidamos para hoje à noite?

Saltitando bem na frente, Adika cantarolou sua resposta:

- Todos os nossos amigos, Mama. (CHAMBERLIN; CHAMBERLIN, 2007, n.p, destaques do autor e autora).

A surpresa de Mama Panya foi ao perceber que cada pessoa convidada chegou a sua casa levando um alimento: Swandi e Naiman levaram duas cabaças cheias de leite e um pequeno balde de manteiga; Odolo levou três peixes; já Gamila levou bananas e disse: “- Bananas ficam ótimas com panquecas" (CHAMBERLIN; CHAMBERLIN, 2007); também chegaram Bibi e Bwana Zamenna com um pacote cheio de farinha para mais panquecas; e, por fim, Kaya levou sal e cardamomo, além de sua mbira ${ }^{8}$ para alegrar a noite. Então, o "banquete começou assim que todos se sentaram debaixo do baobá para comer as panquecas de Mama Panya. Mais tarde, Kaya tocou a mbira e Mzee Odolo cantou, um pouquinho desafinado" (CHAMBERLIN; CHAMBERLIN, 2007, n.p).

Não somente nessa história mas em várias narrativas africanas, o baobá é uma figura emblemática: é a árvore em torno da qual ocorre o congraçamento, o ritual de alimentação do corpo e do espírito (por meio da música e dos risos, como é descrito em As panquecas de Mama Panya, por exemplo). Mas também aparece em textos autobiográficos, como em O baobá e eu, de Georges Gneka (2005). Na Costa do Marfim, mais especialmente na aldeia de Sekleke, vivia sua avó, Towenin. As melhores lembranças do autor em relação àquela terra referem-se ao baobá:

Nas noites de lua cheia, todo o vilarejo sentava debaixo de uma grande árvore, para ouvir e trocar umas histórias, que falavam de animais, de água, de fogo, do por que disso, por que daquilo. Eu era muito curioso e ficava intrigado. Por que os velhos sempre se reuniam, por horas, discutindo debaixo da Árvore da palavra, que era como a chamavam? Como era imponente, com seus braços levantados na direção dos céus, parecendo implorar eternamente algo para o divino. Será que ela levava

\footnotetext{
${ }^{8} \mathrm{Na}$ definição técnica, mbira é o nome "de vários tipos de madeira na África e estendido como denominação aos instrumentos como 'xilofone' ou 'sansa'. É encontrado também com as denominações 'mbila' e 'mebira' (África)" (FRUNGILO, 2003, p. 208). Mais do que isso, a mbira é primordial para alguns povos, como os Shona, por exemplo, por ser o instrumento utilizado para rituais religiosos e comunicação com os ancestrais.
} 
mesmo as mensagens dos velhos para o além? (GNEKA, 2005, p. 22, destaques do autor).

Essa passagem ratifica uma interessante tríade: o espírito, a comunicação e a comunidade. As mensagens são enviadas quando os velhos e velhas, juntamente com todo o vilarejo, se reúnem, demonstrando a força da comunidade. Em ambas as narrativas - de Mama Panya e de Gneka - o baobá é o instrumento para a ligação da comunidade e para a troca de experiências, resolução de conflitos ou aprendizagem de algo útil para o grupo. Para Sobonfu Somé (2007, p. 35) a “comunidade é o espírito, a luz-guia da tribo". Sem a comunidade há uma sobrecarga individual e "é difícil uma única pessoa ter uma visão ampla” (SOMÉ, 2007, p. 37). A necessidade de estar em grupo é, portanto, um princípio fundamental para a manutenção da força interior de cada vivente.

O objetivo da comunidade é assegurar que cada membro seja ouvido e consiga contribuir com os dons que trouxe ao mundo, da forma apropriada. Sem essa doação, a comunidade morre. E sem a comunidade, o indivíduo fica sem um espaço para contribuir. A comunidade é uma base na qual as pessoas vão compartilhar seus dons e recebem as dádivas dos outros (SOMÉ, 2007, p. 35).

O protagonista do livro O chamado de Sosu, de Meshack Asare (2005), também viveu uma experiência que realça a importância de cada membro da comunidade, reconhecendo que é por meio dela que "as pessoas se reúnem para realizar algo específico, para ajudar os outros a realizarem seu propósito e cuidar umas das outras" (SOMÉ, 2007, p. 35). Sosu é um menino que habita uma aldeia "numa estreita faixa de terra entre o mar e laguna" (ASARE, 2005, n.p). O que conhece da aldeia é da época “em que era tão pequeno que a mãe podia carregá-lo nas costas. Isso já faz muito tempo, quando todos desejam ternamente vê-lo em pé andando. Mas não aconteceu" (ASARE, 2005, n.p). Sua condição física o limitou a ver o mundo apenas do interior de sua casa.

Ainda que tivesse aprendido a ler e a escrever por intermédio de seu irmão Fafa e sua irmã Bubu, que iam para a escola e lhes ensinavam as lições aprendidas, a solidão de Sosu só não era maior por causa da companhia de seu cachorro, Fusa. Mas tudo mudou para ele e para toda a comunidade quando, numa segunda-feira, quase todo mundo já estava longe da aldeia cuidando dos afazeres: as crianças na escola da aldeia vizinha, as mulheres nas plantações e os homens pescando. Neste dia, uma terrível tempestade fez com que o mar invadisse a aldeia que naquele momento só estava 
ocupada por pessoas "mais velhas e fracas para fazer alguma coisa, e eram muitas. Com frequência, elas eram deixadas com crianças pequenas. Se o mar continuasse subindo, todos poderiam ficar presos e se afogar" (ASARE, 2005, n.p).

Foi Sosu, com apoio de seu amigo Fusa, que pensou num modo de avisar aos adultos o que se passava na aldeia: tocando os tam-tans, que estavam atrás da casa do chefe da aldeia. "Até hoje Sosu não sabe de onde tirou a força que deu vigor a suas frágeis pernas e de onde veio a coragem para seguir adiante. De alguma maneira ele foi se arrastando, curvado para enfrentar o vento uivante, engatinhando pelas poças de água" (ASARE, 2005, n.p). Assim ele conseguiu alertar às demais pessoas que voltaram de seus afazeres para resgatar a todos.

Nessa história, outro aspecto que denota a ligação comunitária é a força ancestral. Embora Sosu não saiba de onde vieram as forças, para a tradição africana ele não estava sozinho pois seus ancestrais o protegeram: "O espírito de um ancestral tem a capacidade de ver não só o mundo invisível do espírito, mas também este mundo. Assim, serve como nossos olhos dos dois lados. É esse poder dos ancestrais que nos ajuda a direcionar nossa vida e evitar os abismos" (SOMÉ, 2007, p. 26). E lembrando que as crianças têm uma intensa e especial ligação com o espírito ancestral, cabe observarmos mais de perto como a literatura infantil captou essa relação.

\section{A ligação ancestral}

Ainda que haja significativas diferenças entre a literatura infantil de contextos culturais africanos e a de contextos culturais afro-brasileiros, a reconexão ancestral como marca literária é permanente em ambas. A principal diferença entre as duas é que na produção africana é quase que totalmente ausente a experiência do racismo como tema, conforme constatou Maria Anória de Jesus Oliveira (2010) ${ }^{9}$; ao passo que a produção brasileira recorre à construção de personagens que procuram por suas origens africanas diante de um total ou parcial desconhecimento ou em decorrência de buscas por respostas sobre como enfrentar as experiências de discriminação racial. Mas, em

\footnotetext{
${ }^{9}$ Em análise do contexto de produção literária infantojuvenil moçambicano, a autora assim constatou: "Alberto da Barca, entre outros escritores moçambicanos, tais quais, Angelina Neves e Rogério Manjate, se expressaram em relação ao fato de se produzir livros voltados para o universo infantil e juvenil no seu país, contendo majoritariamente personagens negros. Para todos apenas se representa a população que é majoritária, até porque não lhes ocorre a discriminação racial. Nesse sentido, Alberto da Barca ressaltou que, 'Se por um lado, no caso do Brasil, ainda se está à procura de um espaço para os personagens negros na vasta literatura infanto-juvenil, nosso contexto é outro, estamos à procura de um espaço para a literatura infantil como forma de expressão literária [...]"” (OLIVEIRA, 2010, p. 266).
} 
ambas, o exercício de se vincular aos entes espirituais - expressos como ancestrais perpassa as experiências das personagens. É um exercício que leva, invariavelmente, à incessante busca por reconexão, talvez porque, concordando com Somé (2007, p. 69), "até os cinco ou seis anos as crianças lembram-se de tudo perfeitamente, mas, depois disso, algo começa a acontecer no corpo, que as faz esquecer".

Seja em um ou outro contexto, pensar a ancestralidade envolve pensar a memória. Para Eduardo Oliveira (2007, p. 245), a "ancestralidade é um tempo difuso e um espaço diluído" que contém dobras, as memórias.

A memória é precisamente os fios que compõem a estampa da existência. A trama e a urdidura são os modos pelos quais a estampa é tecida. A estampa é uma marca identitária no tecido incolor e multiforme da experiência. Jamais temos acesso à matéria-prima do tecido. Sabemos de sua existência simplesmente porque podemos identificar a estampa impressa sobre ela. Podemos captar seu sentido, mas não alcançamos seu significado. Apesar do sentido ser mais profundo que o significado, acessamos antes o mistério do seu exterior e perdemos seu significado (OLIVEIRA, 2007, p. 245-246).

E por mais que a "matéria-prima" seja inacessível, as personagens escolhidas para este texto parecem construir seus caminhos pelos fios da memória, sempre com vistas a captar o máximo possível do sentido, talvez por entenderem, consciente ou inconscientemente, que os espíritos nos ajudam a "realizar o propósito de nossa própria vida e a manter nossa sanidade" (SOMÉ, 2007, p. 25).

Em Irmã-Estrela, de Alain Mabanckou (2013), o protagonista, um menino de 10 anos, se encontra ancestralmente com o espírito de sua irmã:

[...] eu me sentava no meio do quintal e levantava bem a cabeça, porque minha mãe havia me dito que eu tinha uma irmã mais velha que morava no céu junto dos anjos!

Às vezes, eu esperava por meia hora. De repente, via uma estrela, uma estrela bem pequenina, que brilhava mais que as outras. Eu a observava atentamente. Via mover-se; depois, separar-se das outras, sorrir para mim, esconder-se por um momento entre as nuvens e, então, reaparecer. [...] Sabia que essa estrela era a minha irmã mais velha, falecida dois anos antes de eu nascer. Eu lhe dei um nome bonito: Irmã-estrela (MABANCKOU, 2013, p. 6).

Se a memória é o corpo do espaço ancestral Oliveira (2007, p. 246), manter viva a memória da irmã é, por consequência para o menino, uma manutenção da sua ancestralidade. E essa ligação entre o menino e sua irmã é, antes de tudo, um movimento iniciado pela mãe, em reconhecimento da necessidade de contato espiritual 
e ancestral desde a infância: "Precisamos tentar não educar nossas crianças longe do espírito, para que elas não tenham de despender esforço para se reconectar, quando crescerem. Quando já sabem que têm um espírito, todo o resto é compreendido. Essa compreensão torna a vida mais fácil para elas" (SOMÉ, 2007, p. 34).

Mas a experiência ancestral na literatura de temática da cultura africana e afrobrasileira não se estabelece apenas entre os seres viventes e não viventes, mas também entre divindades e humanos ou mesmo somente entre divindades. Ombela (ONDJAKI, 2014) é uma deusa responsável por criar a chuva: "Dizem os mais-velhos que a chuva nasceu da lágrima de Ombela, uma deusa que estava triste" (ONDJAKI, 2014, n.p). Preocupada, no entanto, em não matar os bichos nem as pessoas, ela decidiu chorar lágrimas com muito sal e que alimentassem todos os mares. Em conversa com seu pai, ao ouvir que quando está triste ele fica "mais pequenino" (ONDJAKI, 2014, n.p), surge uma dúvida em Ombela: “- Os deuses podem ficar mais pequenos?” (ONDJAKI, 2014, n.p). A resposta de seu pai surpreendeu a menina, pequena deusa: “- Assim como a lua tem muitas faces, no mundo, por vezes, faz Inverno e outras vezes faz Verão. Mesmo nós, os deuses, não podemos sempre estar felizes. Se é hora de sorrir, deves sorrir. Se precisas chorar, deves chorar" (ONDJAKI, 2014, n.p). O conflito vivenciado na trama evidencia como, na tradição africana, não há uma noção de perfeição atribuída a divindades. São seres falhos, incompletos e inclusos, à imagem e semelhança dos humanos.

Oliveira (2007) nos lembra de como, para as matrizes africanas, as noções de harmonia e de conflito também acionam sentidos menos maniqueístas, como convencionamos entendê-las no ocidente: "Existe a harmonia e existe o conflito. Apenas que o conflito é ritualizado e a harmonia não é signo de perfeição na experiência africana" (OLIVEIRA, 2007, p. 247). Divindades africanas, sejam elas quais forem, vivenciam as experiências do conflito, da tensão, da disputa e da harmonia mediados por um sistema ético que permite "a expressão das energias, e quando elas se antagonizam é por meio da tradição ética da experiência africana que as forças - e seu poder - restabelecem seu equilíbrio para manter a vida do universo e do indivíduo" (OLIVEIRA, 2007, p. 256).

Os orixás sintetizam muito bem essa tensão responsável por gerar uma "unidade ética que preserva o mundo criado" (OLIVEIRA, 2007, p. 256). Oiá, do livro OmoObá: histórias de princesas, de Kiusam de Oliveira (2009, p. 9), era "uma menina guerreira [...] [que] tinha conhecimentos que ninguém mais possuía: ela podia 
transformar-se em búfalo". Seu conflito ocorre quando seu amigo Ogum descobre seu mistério: “- Quer dizer que este é o seu segredo de força, de determinação, de graça e de beleza?" (OLIVEIRA, 2009, p. 15). A explicação de Oiá explicita o quanto o sistema ético reflete a relação ancestral entre corpo e espírito:

- Toda menina, toda mocinha e toda mulher tem dentro de si a força e o poder de um animal selvagem sagrado que, em certos momentos, devem ser colocados para fora, devem explodir para o universo a mensagem de que fazemos parte de tudo isto. Quando colocamos essa força para fora, muitos meninos e meninas, mocinhos e mocinhas, homens e mulheres não compreendem e, por isso, devemos mantê-la em segredo (OLIVEIRA, 2009, p. 15).

Tal narrativa evidencia que a ancestralidade, expressa, nesse caso, num animal grandioso e forte, "é uma categoria de relação, ligação, inclusão, diversidade, unidade e encantamento. Ela, ao mesmo tempo, é enigma-mistério e revelação-profecia. Indica e esconde caminhos. A ancestralidade é um modo de interpretar e produzir a realidade" (OLIVEIRA, 2007, p. 257).

Mas voltando à ligação ancestral entre os seres humanos com os espíritos, é válido considerar que não se trata de uma ligação meramente vertical, já que "somos os olhos dos ancestrais neste mundo" (SOMÉ, 2007, p. 67) ou, em outras palavras, "a ancestralidade é o que dá forma ao corpo e, inversamente, o corpo dá conteúdo à ancestralidade" (OLIVEIRA, 2007, p. 256). Assim, os espíritos existem por nossa existência. Além disso, essa ancestralidade não é reflexo somente de origens hereditárias imediatas:

Quando falamos sobre conexão com os espíritos de ancestrais, muitas pessoas entendem que nos referimos a nossos ancestrais diretos. Mas isso seria difícil. Frequentemente, nem conhecemos nossos avós. Existe um conjunto de ancestrais - não precisa ser uma pessoa ou espírito que conhecemos ou que imaginamos. Pode ser uma árvore lá fora. Pode ser uma vaca, nosso cão ou gato, em casa. O tataravô, que morreu há muitas gerações, pode ter se unido ao conjunto de espíritos, e o tataraneto nem consegue identificá-lo. É possível que seja o riacho correndo ao longe. Portanto, o que importa é compreender que qualquer pessoa que perdeu o corpo físico é um potencial ancestral. Você atrairá muitos espíritos se simplesmente expressar seu anseio pelo apoio dos ancestrais (SOMÉ, 2007, p. 28).

Exemplo disso são duas meninas, Bruna e Tayó. Escrita por Gercilga de Almeida (2012), a personagem Bruna é uma menina solitária, que encontra em sua avó, Nanã, o aconchego de que precisa, ouvindo histórias da terra natal. As outras meninas da aldeia de Bruna não brincavam com ela e, por isso, quando ela aprendeu com seu tio 
a moldar uma galinha d'Angola, o sentimento de solidão diminuiu um pouco. Já o conflito de Tayó, de Kiusam de Oliveira (2013), relaciona-se à discriminação por causa de seu cabelo. Entristecida por ouvir que seu cabelo é "ruim":

[...] Tayó projeta em seu penteado, mesmo sem se dar conta disso, todas as memórias do sequestro dos africanos e das africanas, sua vinda à força para o Brasil nos navios negreiros, os grilhões e correntes que aprisionavam seus corpos. Tudo isso está bem guardadinho lá no fundo da sua alma (OLIVEIRA, 2013, p. 28).

Os conflitos de ambas são solucionados pela forte ligação que mantêm com seus espíritos ancestrais, estimulada pelos sonhos: "Certa noite, Bruna sonhou com a Conquém descendo por uma corrente de ouro. Ela era muito engraçada, trazia uma bolsa pendurada e, com suas patinhas, espalhava a terra, que caía do céu, na Terra" (ALMEIDA, 2012, n.p). Segundo sua avó essa história envolvia Ọsun, uma menina que, como Bruna, também se sentia só e para "lhe fazer companhia resolveu criar o que ela chamava de 'o seu povo"” (ALMEIDA, 2012, n.p).

Também Tayó projeta em seus sonhos a ligação que nutre com os espíritos ancestrais: "Nem enquanto dorme seu penteado fica desabitado. Por vezes, ele é povoado por seus ancestrais, os zelosos ORIXÁS, que a protegem e não a deixam se esquecer de que é descendente da mais nobre CASTA REAL AFRICANA" (OLIVEIRA, 2013, p. 32, destaques da autora). O sonho, para ambas, é o principal instrumento de conexão ancestral e um elemento marcante das sociedades africanas:

Outra coisa que às vezes incomoda os ocidentais nas histórias africanas é a frequente intervenção de sonhos premonitórios, previsões e outros fenômenos do gênero. Mas a vida africana é entremeada deste tipo de acontecimentos que, para nós, são parte do dia-a-dia e não nos surpreendem de maneira alguma. Antigamente, não era raro ver um homem chegar a pé de uma aldeia distante apenas para trazer a alguém um aviso ou instruções a seu respeito que havia recebido em sonhos. Feito isso, simplesmente retornava, como um carteiro que tivesse vindo entregar uma carta ao destinatário. Não seria honesto de minha parte deixar de mencionar este tipo de fenômeno no decorrer da história, porque faziam e sem dúvida, em certa medida ainda fazem parte de nossa realidade vivida (BÂ, 2003, p. 15).

Cabe, quase ao término deste texto, ressaltar que as experiências das crianças aqui presentes evidenciam que "a ancestralidade é um território sobre o qual se dão as trocas de experiências: signicas, materiais, linguísticas, etc.” (OLIVEIRA, 2007, p. 257). Tais trocas são, invariavelmente, mediadas pelo encantamento, mas não um encantamento exótico aos moldes ocidentais. O encantamento, nessa perspectiva, é 
"uma atitude, simplesmente. [...] Encantamento tem a ver com o olhar. O olhar encantado constrói um mundo encantado" (OLIVEIRA, 2007, p. 258-259). Talvez por isso o interesse sobre as crianças, já que elas detêm, por excelência, a capacidade de encantar-se e encantar o mundo.

\section{Para continuar pensando...}

Assim como já destacado anteriormente, na tendência da literatura infantil que envolve o resgate da herança e da ancestralidade africana Araujo (2017) está a presença dos espíritos ancestrais auxiliando na resolução de conflitos, tal como aconteceu com várias das crianças aqui aludidas. Mas também essas narrativas mostram o quanto cada ser no mundo tem um propósito, sejam eles reais ou fictícios.

Cada pessoa escolhe seu propósito de vida antes do nascimento. [...] Quando uma mulher está grávida, faz-se um ritual de audiência. Nesse ritual, os anciãos perguntam à criança: 'quem é você? Por que está vindo? Este mundo está muito complicado, por você resolveu vir? O que podemos fazer para facilitar sua jornada?'

O bebê usa a voz da mãe e responde: 'este sou eu. Estou vindo ajudar a manter o conhecimento dos ancestrais', ou 'estou vindo para fazer tal e tal'. Com base nessa informação, os anciãos preparam um espaço de ritual apropriado para receber a criança e têm tudo pronto antes dela nascer (SOMÉ, 2007, p. 68-69).

Essa mesma compreensão de mundo, ou "cosmopercepção", como propõe Oyèrónkẹ́ Oyěwùmí $(1990)^{10}$, que reconhece a criança como um ser agente desde antes de seu nascimento, membro ativo e ligado umbilicalmente com a comunidade, também foi relatada por Maathai (2007, p. 20):

Quando um bebê vinha se juntar à comunidade, realizava-se um belo e prático ritual que apresentava a criança à terra de seus ancestrais e preservava o mundo em abundância e riqueza que brotava daquele solo. [...]

Enquanto as mulheres reuniam as comidas rituais, o pai da criança sacrificava o cordeiro e assava um pedaço de sua carne. As bananas e as batatas-doces também seriam assadas e dadas à nova mãe junto com a carne e a cana. Ela devia mastigar pedaços pequenos de cada um desses alimentos, alternadamente, e, depois, pôr um pouco do suco na boquinha do bebê. Esta foi a minha primeira refeição. Antes mesmo de mamar, engoli o suco de banana verde, de cana-de-açúcar arroxeada, de

\footnotetext{
${ }^{10}$ Para Oyèrónké Oyěwùmí (1990, p. 3) o termo "cosmovisão", "que é usado no Ocidente para resumir a lógica cultural de uma sociedade, capta o privilégio ocidental do visual". Esse privilégio, para a autora, pode preterir outros sentidos. Assim, o 'termo 'cosmopercepção' é uma maneira mais inclusiva de descrever a concepção de mundo por diferentes grupos culturais".
} 
batata-doce e de um cordeiro cevado, tudo produzido pela terra da região. Sou tão filha do chão em que nasci quanto de meu pai, Muta Njugi, e da minha mãe, Wanjiru Kibicho [...].

Ser criança, nas sociedades tradicionais africanas, significa existir e coexistir desde sempre, sobretudo porque se entende que o protagonismo das escolhas e o conhecimento dos mistérios espirituais não são menores quando se é pequeno. Pelo contrário, como destacou Somé (2007, p. 69), “crescer é um processo de esquecimento. Este corpo, dizem os anciãos, tira certas coisas de nós quando crescemos".

As histórias das crianças presentes neste texto também reificam que a "maioria das culturas africanas encerra sua sabedoria na forma narrativa dos mitos. Talvez porque os mitos não segreguem as esferas do viver. Não separa religião de política, ética de trabalho, conhecimento de ação" (OLIVEIRA, 2007, p. 237).

Fica evidente, também, para quem pensa a existência da criança como ser desde sempre, o quanto a literatura infantil é rica. E se pensarmos que ambas - as crianças e a literatura a elas endereçada - foram historicamente relegadas a um patamar de inferioridade, as provocações feitas pelas suas vozes presentes neste texto acionam nossos ouvidos, corações e mentes para reconsiderarmos, também academicamente, o espaço social da produção cultural da infância. Ser criança, ainda que seja ser pequeno, não significa ser menor.

Em tempos estranhos, de propagação do ódio, do desamor e do desprezo ao outro, aumenta a preocupação sobre o quanto retrocederemos na liberdade cultural e espiritual das pessoas, em especial das crianças em nosso país, que vivem uma relação inversamente proporcional de reconhecimento social às crianças das sociedades tradicionais africanas: quanto menos idade têm, menos direitos possuem e são menos consideradas como seres completos em sua existência. $\mathrm{O}$ desejo é que a literatura continue despertando adultos e adultas a reconhecerem a potência de vida presente nas crianças, tais como elas são: crianças.

$$
\text { Recebido em: 22-02-2019 Aceito em: 11-03-2019 }
$$

\section{Referências}

ALMEIDA, Gercilga de. Bruna e a galinha d'Angola. Rio de Janeiro: EDC - Ed. Didática e Científica; Pallas Editora, 2011.

ARAUJO, Débora Oyayomi. Qual o lugar ocupado pelas personagens negras na literatura infantil brasileira? Refletindo sobre estereótipos e originalidade. TOM 
Caderno de Ensaios da UFPR, v. 3, p. 20-42, 2017.

ASARE, Meshack. O chamado de Sosu. Ilustrações do autor. Tradução de: PRADES, Maria Dolores. São Paulo: Edições SM, 2005. (Cantos do mundo).

CÉSAR, Chico. Mama África. In: Cuscuz Clã. Rio de Janeiro: Mza Music, 1996. 1 CD-ROM.

CHAMBERLIN, Mary; CHAMBERLIN, Rich. As panquecas de mama Panya. Ilustrações de: CAIRNS, Julia; tradução de: MESQUITA, Cláudia Ribeiro. São Paulo: Edições SM, 2005. (Cantos do mundo)

DEBUS, Eliane. A temática da cultura africana e afro-brasileira na literatura para crianças e jovens. Centro de Ciências da Educação. São Paulo: Cortez, 2017.

DELEUZE, Gilles; GUATTARI, Félix. KAFKA: por uma literatura menor. Tradução de: GUIMARÃES, Júlio Castañon. Rio de Janeiro: Imago Editora Ltda, 1977.

FERNANDES, Maria Celestina. Kalimba. Ilustrações de: MANCUSO, Bruna. São Paulo: Editora Kapulana, 2015. (Série Vozes da África: Angola).

FRUNGILO, Mário D. Dicionário de percussão. São Paulo: Editora Unesp; Imprensa Oficial do Estado, 2003.

GALLO, Sílvio. Em torno de uma educação menor. Educação e realidade. v. 27, n. 2, p. 169-178, jul-dez, 2002.

GNEKA, Georges. O baobá e eu. In: A semente que veio da África. Ilustrações de: TADJO, Véronique. São Paulo: Salamandra, p. 18-23, 2005.

HAMPATÉ BÂ, Amadou. Amkoullel: o menino fula. Casa das Áfricas. São Paulo: Palas Athena, 2003.

IYAGUNÃ, Dalzira Maria Aparecida. Templo religioso, natureza e os avanços tecnológicos: os saberes do candomblé na contemporaneidade. Dissertação (Mestrado em Tecnologia). Universidade Tecnológica Federal do Paraná - Curitiba, 2013.

JESUS, Clementina de. Canto II. In: O Canto dos Escravos. São Paulo: Estúdio Eldorado, 1982. $1 \mathrm{LP}$, prensado.

LARROSA, Jorge. O enigma da infância ou o que vai do possível ao verdadeiro. In: Imagens do Outro. Petrópolis, RJ: Vozes, p. 67-86, 1998.

MABANCKOU, Alain. Irmã-estrela. Ilustrações de: GUEYFIER, Judith. Tradução de: CADERMATORI, Ligia. São Paulo: FTD, 2013.

OYĚWÙMÍ, Oyèrónkẹ́. Visualizing the Body: Western Theories and African Subjects In: OYĚWÙMÍ, Oyèrónkẹ. The invention of women: making an African sense of western gender discourses. Minneapolis: University of Minnesota Press, 1997, p. 130. Tradução para uso didático de wanderson flor do nascimento.

OLIVEIRA, Eduardo David. Filosofia da ancestralidade: corpo e mito na filosofia da 
educação brasileira. Curitiba: Editora Gráfica Popular, 2007.

OLIVEIRA, Maria Anória de Jesus. Personagens negros na literatura infantojuvenil no Brasil e em Moçambique (2000 - 2007): entrelaçadas vozes tecendo negritudes. Tese (Doutorado em Letras) - Universidade Federal da Paraíba, 2010.

OLIVEIRA, Kiusam de. Omọ-Obá: histórias de princesas. Ilustrações de:

MARINHO, Josias. Belo Horizonte: Mazza Edições, 2009.

OLIVEIRA, Kiusam de. O mundo no black power de Tayó. Ilustrações de: BORGES, Taísa. São Paulo: Peirópolis, 2013.

ONDJAKI. Ombela: a origem das chuvas. Ilustrações de: CAIANO, Rachel. Rio de Janeiro: Pallas Mini, 2014.

ROSEMBERG, Fúlvia. A criança pequena e o direito à creche no contexto dos debates sobre infância e relações raciais. In: BENTO, Maria Aparecida Silva (Org.). Educação infantil, igualdade racial e diversidade: aspectos políticos, jurídicos, conceituais. São Paulo: Centro de Estudos das Relações de Trabalho e Desigualdades - CEERT, p. 1146, 2012.

SOMÉ, Sobonfu. O espírito da intimidade: ensinamentos ancestrais africanos sobre maneiras de se relacionar. 2. ed., São Paulo: Odysseus, 2007. 